\title{
AS VÁRIAS INSTTTUCIONALIZAÇÕES DA TEORIA NEO-INSTITUCIONAL
}

\author{
Por Charles Kirschbaum \\ Professor assistente de Organização e Estratégia, Ibmec - São Paulo \\ kircharles@gmail.com
}

\section{João Marcelo Crubellate}

Professor adjunto, Programa de Pós-Graduação em Administração, Universidade Federal do Paraná

jmcrubellate@aol.com

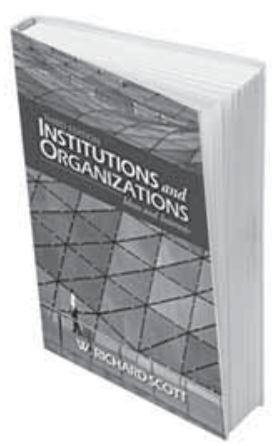

INSTITUTIONS AND ORGANIZATIONS: IDEAS AND INTERESTS

De W. Richard Scott

Estados Unidos: Sage Publications, 2008. 280 p.
0 recém-lançado Institutions and 0 rganizations, deW. Richard Scott, um dos princi pais representantes da teoria das organizações desde a década de 1960, continua a ser fonte pedagógica para os iniciantes no neo-institucionalismo e fonte de debate para os iniciados.

Fundamentada na teoria institucional, essa pode ser considerada a sua obra mais relevante, referência de primeira grandeza para os pesquisadores dedicados ao entendimento de problemas organizacionais, de estratégia, de gestão, dentre outros. 0 livro destaca-se pelo tratamento dos diversos temas da teoria institucional de modo panorâmico, permitindo adequado entendimento da evolução das idéias principais. Ademais, 0 autor discute com profundidade certos aspectos da teoria que a distinguem, tornado o livro recomendável para 0 entendimento geral do novo institu- cionalismo e para pesquisas acerca das diversas temáticas a ele vinculadas.

Quanto ao seu conteúdo, podemos perguntar o que há para debater, ainda, em torno do "neo-institucionalismo sociológico" (NIS)? Suas contribuições já não estão sedimentadas? N esta terceira edição, o autor propõe que a perspectiva institucional finalmente atingiu sua maturidade. Ao discutir al guns elementos centrais da teoria, remete-se ao cerne de sua institucional ização na disciplina de Teoria Organizacional. Sendo assim, esta resenha convida o leitor a pensar criticamente al guns elementos do neo-institucionalismo.

O NIS foi difundido na academia brasileira associado principalmente a dois fenômenos: decoupling e isomorfismo. 0 primeiro remete à separação entre estruturas formais e práticas operacionais, enquanto 0 segundo está associado às razões pelas quais as firmas tendem a convergir em torno de práticas comuns. Referentemente a esses dois fenômenos, surge a idéia de que o NIS (1) busca explicar o comportamento irracional das empresas e (2) é uma teoria mais aplicável em contextos "altamente simbólicos", nos quais a eficiência técnica não é imperativa. Como mostra Dobbin (Cultural models of organization: the social construction of rational organizing principles. In: CRANE, D. (Ed). The Sociology of Culture. Oxford, UK: Blackwell, 1994, p. 117-141.), essa idéia foi associada principal mente aos primeiros estudos neo-institucionalistas.

Em contraste, esses dois fenômenos apontam para um posicionamento paradigmático em relação às decisões empresariais: trata-se, então, de entender como as dimensões técnica e simbólica estão imbricadas (SCOTT, 
2008, p. 217). Passa-se, assim, à investigação da racionalidade como local, histórica e social mente construída. Se concordarmos com Dobbin em que o NIS rompe com a dicotomia, herdada de Parsons, entre técnica e cultura, observaremos então um redirecionamento à abordagem weberiana de sobreposição, interação e choque entre formas de racionalidade (SWEDBERG, R. Max Weber and the Idea of Economic Sociology. Princeton: Princeton University Press, 2000. 328 p.). N esta edição, Scott (2008) nos traz exemplos de trabal hos empíricos que mostram como as lógicas institucionais emergem, como os processos de institucionalização se desenvolvem e como os atores sociais avançam suas prerrogativas por meio das (e guiados pelas) instituições. Percebe-se, então, a ênfase na dinâmica dos processos.

Scott (2008) insiste em colocar sob o mesmo guarda-chuva elementos teóricos oriundos de três orientações institucionalistas, isto é, o institucionalismo sociológico, o político e o econômico. Seu esforço foge da identificação de um denominador comum para entender o processo de institucionalização como inerentemente histórico. N essa vertente, Scott (2008) rompe com a tradição positivista entre os neo-institucional istas, procurando entender a formação e transformação das instituições em seus diversos níveis. Assim, o autor não poderia ser mais weberiano: em sua sociologia, os "tipos-ideais" são historicamente contingentes. Scott (2008) aprofunda ainda mais sua revisão da abordagem evolucionária na economia e das contribuições processualistas, inspiradas no estruturacionismo de Giddens.

0 esforço de Scott (2008) em abrigar em seu livro as várias correntes do institucionalismo com ênfase na sociologia pode ser observado pelo seu famoso quadro síntese dos "três pilares" do institucionalismo (2008, p. 79). Essa acomodação de várias vertentes trouxe críticos entre vários grupos. Por um lado, Hirsch ("Sociology without social structure: neoinstitutional theory meets brave new world". American Journal of Sociology, v. 102, n. 6, p. 1702, 1997), em uma resenha da primeira edição, acusou 0 autor de separar artificialmente os elementos coercitivos, normativos e cognitivos das instituições. Ao insistir em que Scott estava enviesado em direção à dimensão cognitiva, Hirsch (1997) desafiou os neo-institucionalistas a contestar a seguinte proposição: o neo-institucionalismo concebe as estruturas como existentes apenas na dimensão cognitiva, retirando a sua realidade coercitiva. Em resposta, Scott ("Response to Hirsch's review essay". American Journal of Sociology, v. 103, n. 4, p. 1047-1048, 1998) reforça que as dimensões propostas no livro são analíticas, e, portanto, podemos observá-las operando ao mesmo tempo.

Entre os pesquisadores da tradição neo-institucionalista, a crítica se dá ao revés: a tentativa de acomodação de várias teorias e seu alinhamento em torno dos pilares acaba levando à incompatibilidade e contradição. Trabalhos como o de Edelman, Uggen e Erlanger ( "The endogeneity of legal regulation: grievance procedures as rational myth. The American Journal of Sociology, v. 105, n. 2, Sep., p. 406-454, 1999) mostram que as regulamentações formais manifestam-se nas práticas apenas pela mediação dos esquemas interpretativos dos atores sociais. Se tomarmos isso como base para a análise da formação e transformação das instituições formais, admitimos uma penetração maior da sociologia jurídica nos estudos neoinstitucionais. Assim, os detratores de Scott buscam delimitar o campo do NIS e estabelecer um consenso sobre 0 que significa "instituição" na tradição cognitivista. Fiéis à tradição fenome- nológica, eles favorecem o entendimento de instituições como "um comportamento social repetitivo mais ou menos tomado como certo que é sustentado por normas e entendimentos cognitivos que fornecem significado às trocas sociais e permitem a reprodução da ordem social" (GREEN W OOD, R.; OLIVER, C. e outros. Introduction. Em: GREENWOOD, R.; OLIVER, C. e outros ( $E d)$ The Sage Handbook of Organizational Institutionalism. LoS Angeles: Sage, 2008, p. 4).

Nesta última edição, observamos, no capítulo de fechamento, a comemoração da maturidade al cançada pelo neo-institucionalismo, que se reflete, para o autor, em aspectos como (1) a maior coerência do conceito de instituições nos estudos neo-institucionalistas recentes, (2) a mudança de explicações dos fenômenos como produto de mecanismos deterministas em prol de explicações que incluem a capacidade de agência das organizações em relação ao ambiente institucional, (3) o foco no campo como nível analítico, em contraste com a ênfase no nível organizacional, (4) ênfase na mudança institucional, em comparação com a concepção de estruturas estáticas e (5) a mudança de entendimento das instituições como contraponto à racionalidade instrumental, para a sua concepção enquanto pano de fundo para a ação racional.

Scott (2008), por fim, arrisca a "expansão exagerada" da teoria e o prolongamento do déficit de demarcações conceituais. Se, entretanto, Scott optasse por lapidar a teoria e fixar mais alguns pontos, ele poderia levar seus companheiros a restringir o diálogo com outras áreas e disciplinas. Mesmo assim, faz chegar às mãos do leitor uma obra corajosa, pelo fôlego da revisão bibliográfica e principalmente pelas pontes entre as várias vertentes de institucionalismo nas ciências sociais que ousa estabelecer. 